
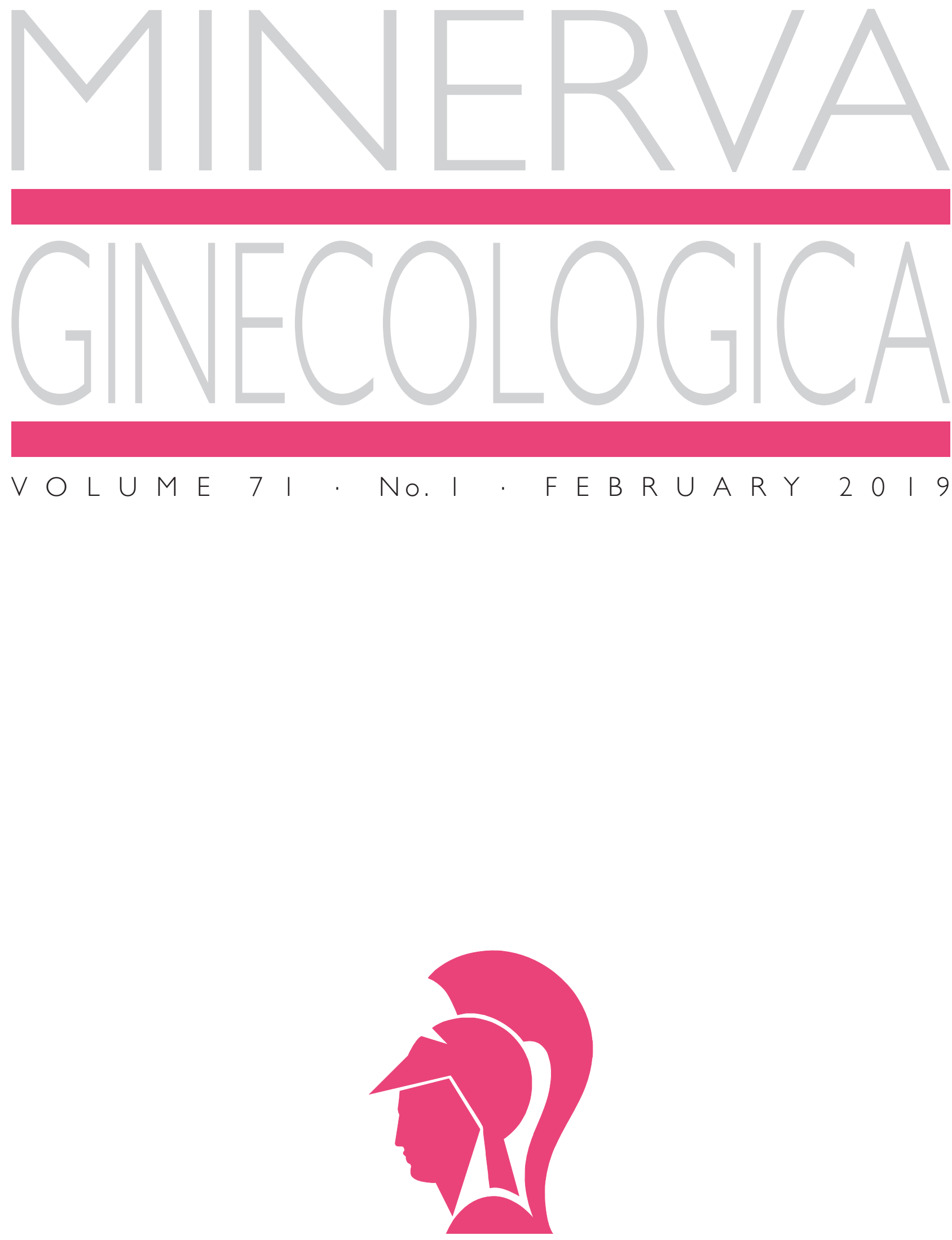

$E D|Z| O N|\cdot M| N E R \vee A$. ME D I C A 


\title{
Update in non-invasive prenatal testing
}

\author{
Valentina D'AMBROSIO 1, Antonia SQUARCELLA 1,2 *, Flaminia VENA 1, Daniele DI MASCIO 1, \\ Sara CORNO ${ }^{1}$, Cristina PAJNO ${ }^{1}$, Maria G. PICCIONI ${ }^{1}$, Roberto BRUNELLI ${ }^{1}$, Antonio PIZZUTI 2 , \\ Pierluigi BENEDETTI PANICI ${ }^{1}$, Antonella GIANCOTTI ${ }^{1}$
}

${ }^{1}$ Department of Gynecological, Obstetrical, and Urological Sciences, Sapienza University, Rome, Italy; ${ }^{2}$ Department of Experimental Medicine, Sapienza University, Umberto I Polyclinic Hospital, Rome, Italy

*Corresponding author: Antonia Squarcella, Department of Gynecological, Obstetrical, and Urological Sciences, Department of Experimental Medicine, Sapienza University, Umberto I Polyclinic Hospital, Viale del Policlinico 155, 00161 Rome, Italy. E-mail: antonia.squarcella@uniroma1.it

\begin{abstract}
A B S T R A C T
Non-invasive prenatal testing (NIPT) has revolutionized the approach to prenatal diagnosis and, to date, it is the most superior screening method for the common autosomal aneuploidies, mostly trisomy 21 . This screening is having a significant population-wide impact on the uptake of conventional screening and diagnostic testing. In recent years, emerging genomic technologies, largely based around next generation sequencing, have expanded the analyses to the sub-chromosomal aneuploidies. However, further clinical validation studies are needed to better characterize this technology. These tests bring advantage through providing a higher diagnostic yield, without risks of miscarriage than previously available diagnostic test, but also raise the question of harms related to an increase in uncertain and unknown results. In view of the revolution brought about by the NIPT, numerous scientific societies have published recommendations regarding the appropriate application of cell-free DNA screening in pregnancy. In this review, we discuss the progress that has been made to date in NIPT.

(Cite this article as: D’Ambrosio V, Squarcella A, Vena F, Di Mascio D, Corno S, Pajno C, et al. Update in non-invasive prenatal testing. Minerva Ginecol 2019;71:44-53. DOI: 10.23736/S0026-4784.18.04306-X)

KEY WORDS: Prenatal diagnosis - Cell-free nucleic acids - Mass screening.
\end{abstract}

$\mathrm{T}$ he goal of prenatal screening for fetal aneuploidies is to identify pregnancies at increased risk for chromosomal disorders using tests with a high detection rates and low false-positive results. In the last decades, we assisted to remarkable advances in prenatal screening for aneuploidy, particularly in the identification of Down Syndrome. ${ }^{1}$ Definitive prenatal diagnosis for chromosomopathies requires invasive sampling followed by karyotype analysis. However, invasive tests are costly and pose a risk of procedurerelated complications including miscarriage, ${ }^{2}$ and therefore they can not be used as a routine in general population. The most common chromosome condition affecting live births is trisomy 21
(Down Syndrome), with an incidence of around 1 in 700 live births. The risk of a live term infant increases with maternal age from $\sim 1$ in 1500 at age 20 years to 1 in 85 at age 40 years. ${ }^{3}$ Starting from 1980, many strategies for the diagnosis of trisomy 21 in low risk population followed one another ${ }^{4}$ (Table I). In many developed countries invasive prenatal tests were offered to pregnant women with advanced age ( $>35$ years), but this strategy was not efficient because fewer than one third of Down syndrome pregnancies were diagnosed prenatally and of those undergoing invasive prenatal diagnosis only about $2 \%$ had fetal karyotype abnormalities. ${ }^{5}$ The introduction of second-trimester serum analyses improved 
TABLE I.-Evolution and performance of different screening test for trisomy 21.

\begin{tabular}{llc}
\hline Year & Methods of screening & $\begin{array}{c}\text { Detection } \\
\text { rate (\%) }\end{array}$ \\
\hline 1970 s & MA & 30 \\
1980 s & MA+ maternal serum marker & $55-60$ \\
& MA + serum AFP, hCG (double & $60-65$ \\
& test) & $60-65$ \\
& MA + serum AFP, free $\beta$-hCG & \\
& (double test) & \\
& MA + serum AFP, hCG, uE3 & \\
& (triple test) \\
1990s & MA + NT & $75-80$ \\
2000 s & MA + NT + free $\beta$-hCG and & $85-90$ \\
& PAPP-A (Combined test) & $93-96$ \\
2011 & Combined test + NB or tricuspid & \\
& flow or DV flow & 99 \\
& cfDNA measured in maternal & \\
\hline
\end{tabular}

MA: maternal age; AFP: alpha-fetoprotein; hCG: human chorionic gonadotropin; $\mathrm{uE3}$ : unconjugated estriol; $\beta$-hCG: $\beta$-human chorionic gonadotrophin; NT: nuchal translucency; PAPP-A: pregnancyassociated plasma protein-A; NB: nasal bone; DV: ductus venosus; cfDNA: cell-free DNA.

the screening performance for aneuploidy from a $30 \%$ of the advanced maternal age to $60-84 \%$ for a false-positive rate of 5\%.6,7 The proportion of Down syndrome pregnancies diagnosed were more than doubled and a chromosomal abnormality was found in as many as $4 \%$ of those designated as "screen-positive."8 Despite the enhancement, this screening strategy was considered still not satisfactory for the high rate of false negative and the late diagnosis of chromosomal abnormalities that could imply pregnancy termination at an advanced gestational age, that could be stressful for the couple. Only with the introduction of the combined test in early 2000 s there was a substantial development in screening performance. This test, performed during the first trimester (11-13 weeks +6$)$, consisted in ultrasound measurement of nuchal translucency thickness (NT) together with maternal serum concentration of placental proteins free beta human chorionic gonadotropin (hCG) and pregnancy-associated plasma protein-A (PAPP-A).6,9 Other aneuploidies, including trisomy 18 (Edwards Syndrome), trisomy 13 (Patau Syndrome) and monosomy X (Turner Syndrome), were also being detected with the widespread use of these screening tests. In 2011, the paradigm of prenatal screening shifted with the introduction of cell- free DNA (cfDNA) test (Table I). The presence of cfDNA in maternal blood has enabled the development of highly sensitive screening tests for fetal aneuploidy, diagnostic tests for fetal RHD type and monogenic disorders. ${ }^{10}$

In this review, we discuss the progress that has been made to date in the analysis of cfDNA in maternal blood for non-invasive prenatal testing (NIPT).

\section{Fetal cfDNA for prenatal diagnosis of aneuploidies}

The presence of fetal DNA in maternal plasma was first reported in 1997 by Lo et al. using conventional polymerase chain reaction techniques to identify Y chromosome-specific DNA sequences. ${ }^{11}$ This study was the landmark for the development of cfDNA screening test.

The discovery of circulating cfDNA in maternal blood has enabled the development of genomics-based non-invasive prenatal testing NIPT to analyze the fetal genome.

This new technology allowed for significant improvements in the detection of pregnancies with trisomy 21 as well as the less common chromosomal disorders. In October 2011, the first commercial laboratory began offering NIPT using cfDNA for screening of common aneuploidy conditions.

\section{Physiology and techniques}

Plasma cfDNA fragments originate from apoptosis of various cells, mostly from hematopoietic cells. ${ }^{12}$ During pregnancy, there is a combination of both maternal and feto-placental derived cfDNA circulating in women plasma. The origin of fetal cfDNA (fetal fraction) is the placental trophoblasts. ${ }^{13}$ Fetal fraction increases with gestational age and amount to $\sim 10 \%$ of the cfDNA in maternal blood. ${ }^{14} \mathrm{~A}$ fetal fraction greater than $4 \%$ is required for reliable analysis, and this value is reached at about 10 weeks of gestation. The most common reason for an interpretable result is a relatively low quantity of placental cfDNA in maternal blood, or low fetal fraction. The cfDNA is no longer available in the maternal circle a few hours after childbirth and is probably eliminated 
through renal excretion. DNA fragments derived from placenta are shorter in length (143 base pairs) than maternally derived DNA fragments (166 base pairs). This difference is very important to improve the accuracy of prenatal aneuploidy screening. ${ }^{15}$

In 2008, in two studies fetuses with chromosomal aneuploidy were identified using massively parallel sequencing of cfDNA from maternal plasma. There are different methods developed for aneuploidy detection: massive parallel sequencing (MPS), chromosome-selective (or targeted) sequencing (CSS) and single nucleotide polymorphism (SNP) based sequencing.

Whole genome MPS process is based on the random or shotgun sequencing of DNA molecules in maternal plasma. ${ }^{16,17}$ Apart from abnormalities involving the entire chromosome, MPSbased analysis of maternal plasma DNA has also been shown to be useful for detecting Down syndrome caused by Robertsonian translocation as well as microdeletions and microduplications. ${ }^{18}$ The whole genome sequencing method allows detection of differences on any chromosome and, depending on the depth of sequencing, detection of less common aneuploidies and subchromosomal abnormalities. ${ }^{19}$ MPS methods statistically calculate the standard deviation of the expected count from each chromosome and allocate a " $Z$ score" for each chromosome. For example, if the number of DNA fragments from chromosome 21 in the test sample is $\mathrm{z}$-score $>3$ this is considered a high-risk result for trisomy $21 .{ }^{20}$

In the CSS approach, the plasma DNA fragments, that are unique to the targeted chromosome, undergo an enrichment process involves a PCR-based reaction. One disadvantage of this approach is that off target chromosomal aneuploidies will not be detected. The statistical method used for CSS combined the woman's prior risk of aneuploidy (based on maternal and gestational age), the target chromosome counts, and the fetal fraction to calculate a final risk using an odds ratio approach. A value of 1 in 100 or greater is considered at high risk. ${ }^{21,22}$

The method, at least two orders of magnitude greater than other reports of multiplexed PCRs SNP-based approaches, employ a massively multiplexed PCR amplification targeting 19,488 SNPs in a single reaction and sophisticated informatics analysis to identify fetal chromosomal copy number. ${ }^{23}$ Among NIPT, SNP-method demonstrates the highest accuracy with sex chromosome aneuploidy detection. It is also the only method capable of detecting triploidy. ${ }^{24}$ Also, SNP-based NIPT will not detect off-target abnormalities.

\section{Biological limits}

Some variables could influence NIPT results. The most common reason for the defined "no call" results is a relatively low fetal fraction. The fetal fraction is low in all those conditions in which there is an increase in the maternal cellular turnover without increasing the placental cellular component. ${ }^{24}$ For example, maternal obesity is a condition associated with a two-fold increase of maternal cfDNA levels in plasma with no significant difference in fetal cfDNA. This fact is due to the increased apoptosis and necrosis present in adipose tissue. ${ }^{25}$ Autoimmune disease could also cause an increase in cell turnover. Indeed, non-pregnant patients affected by systemic lupus erythematosus show elevated levels of circulating cfDNA. ${ }^{26}$ Other statistically significant associations of maternal factors with fetal fraction have been reported, including maternal aneuploidy (47, XXX), maternal mosaicism (45X/46XX), maternal copy number variations, prior organ transplant, maternal medications, smoking and pre-existing hypertension. ${ }^{23}$ In the same case reports maternal malignancy was related to discordant NIPT results. A case series obtained from a total cohort of 125,426 women provided details on 10 women with discordant NIPT results due to an undiagnosed maternal cancer. The cancer types included lymphoma, leukemia, colorectal and anal cancers. In another cohort of the 39 cases with NIPT result indicating multiple aneuploidies, seven were due to asymptomatic maternal malignancies. Also, benign tumors such as uterine fibroids can cause abnormalities in NIPT. ${ }^{26}$ Conditions that could determine "biological false-positives" are confined placental mosaicism, demise of a previously undetected co-twin, maternal copy number variants, or maternal aneuploidy. ${ }^{23,} 27$ Patients should be counseled of these possibilities before proceeding with screening. 


\section{Clinical validity}

cfDNA screening is the most superior screening method for trisomy 21 and has the highest detection rate with the lowest false-positive rate, when compared to other conventional screening tests. An updated meta-analysis, which included studies between January 2011 to January 2015, reports detection rates for common aneuploidies as follows: trisomy $21(99.7 \%)$, trisomy 18 $(98.2 \%)$, and trisomy 13 (99\%), with a combined false-positive rate (FPR) of $0.13 \%$. They also report pooled weighted detection rate of $95.8 \%$ for monosomy $\mathrm{X}$ with a false-positive rate of $0.14 \%$. Other sex chromosome aneuploidies had a pooled weighted detection rate of $100 \%$ and FPR of $0.003 \%{ }^{28}$ (Table II).

\section{Subchromosomal disorders}

Subchromosomal disorders result from submicroscopic genomic imbalances that are too small to be detected by standard karyotyping. Subchromosomal abnormalities (microdeletions and duplications) may result in physical and/or intellectual impairments that can be highly variable and depend on the specific chromosome region and the amount of genetic duplicated or deleted material. ${ }^{29}$ Unlike the risks of aneuploidy that is associated with nondisjunction, the incidence of subchromosomal copy number variations (CNVs) is independent of maternal age. Clinically relevant microdeletions and duplications occur in $1-1.7 \%$ of all structurally normal pregnancies. ${ }^{30}$ Because some infants with subchromosomal abnormalities may benefit from early therapeutic intervention, prenatal detection is important for optimal management. Array comparative genomic hybridization (array$\mathrm{CGH}$ ) is a molecular technology used for the analysis of subchromosomal human karyotype aberrations. Array-CGH allows genome analysis with a resolution of $<1 \mathrm{Mb}$, while conventional cytogenetic examination allows for a 5-10 $\mathrm{Mb}$ resolution. ${ }^{31}$

A meta-analysis conducted by Hillman et al. affirmed that array-CGH detected 3.6\% additional genomic imbalances when conventional karyotyping was normal. This value increased to $5.2 \%$ when the referral indication was a structural malformation on ultrasound. ${ }^{29}$ However, with the introduction of NIPT for aneuploidy screening, many women who previously would have had invasive testing are choosing to avoid these procedures because of the small risk of pregnancy loss.

Submicroscopic genomic alterations are harder to detect non-invasively because of their small size. Therefore, the introduction of a highly accurate non-invasive prenatal screening test that would identify women who are at high risk for microdeletions or duplications would be useful. Proof-of-concept studies have reported the possibility of expanding cfDNA screening to include well-defined microdeletion syndromes (Table III). ${ }^{32-34}$ Recently, a single-nucleotide polymorphism (SNP)-based NIPT was validated for detection of five important, clinically significant microdeletion syndromes: 22q11.2, Prader-Willi, Angelman, cri-du-chat and 1p36 deletion. For all these five disorders, the detection rate for the large causal deletions was $>97 \%$, with a specificity of $>99 \% .32$ Two retrospective cohort studies have been published; 35,36 however, due to the small number of affected fetuses, heterogeneous populations, and incomplete outcome data, the true sensitivity and NPVs in clinical practice are unknown. No prospective clinical trial has been completed for the use of this technology for the detection of microdeletion syndromes. More studies on the argument are needed.

TABLE II.-Performance of cfDNA for aneuploidies.

\begin{tabular}{|c|c|c|}
\hline Aneuploidy & Detection rate $(95 \% \mathrm{CI})^{\mathrm{a}}$ & False positive rate $(95 \% \mathrm{CI})^{\mathrm{a}}$ \\
\hline Trisomy 21 & $99.7 \%(99.1-99.9 \%)$ & $0.04 \%(0.02-0.08 \%)$ \\
\hline Trisomy 18 & $98.2 \%(95.5-99.2 \%)$ & $0.05 \%(0.03-0.07 \%)$ \\
\hline Trisomy 13 & $99.0 \%(65-100 \%)$ & $0.04 \%(0.02-0.07 \%)$ \\
\hline Monosomy X & $95.8 \%(70.3-99.5 \%)$ & $0.14 \%(0.05-0.38 \%)$ \\
\hline Other sex chromosomal aneuploidy & $100 \%(83.6-100 \%)$ & $100 \%(83.6-100 \%)$ \\
\hline
\end{tabular}

aPooled weighted detection rate and false-positive rate from Gil et al. ${ }^{25}$ 
TABLE III.-Microdeletion validated for NIPT according Wapner et al. ${ }^{32}$

\begin{tabular}{|c|c|c|c|c|c|}
\hline Disorder & $\begin{array}{l}\text { Position of } \\
\text { deletion }\end{array}$ & Incidence & $\begin{array}{l}\text { Detection } \\
\text { rate }\end{array}$ & Specificity & Phenotype \\
\hline DiGeorge Syndrome & $22 \mathrm{q} 11.2$ & $1: 1000$ & $>97 \%$ & $>99 \%$ & $\begin{array}{l}\text { Cardiac abnormalities; thymic aplasia; immune } \\
\text { conditions; endocrine, genitourinary and } \\
\text { gastrointestinal problems; developmental } \\
\text { delay }\end{array}$ \\
\hline Prader-Willi Syndrome & $15 \mathrm{q} 11.2-\mathrm{q} 13$ & $1: 10,000-30,000$ & $>97 \%$ & $>99 \%$ & $\begin{array}{l}\text { Hypotonia; feeding difficulties in early infancy; } \\
\text { obesity; hypogonadism; short stature; } \\
\text { behavioral difficulties }\end{array}$ \\
\hline Angelman Syndrome & $15 q 11.2-q 13$ & $1: 12,000-20,000$ & $>97 \%$ & $>99 \%$ & $\begin{array}{l}\text { Severe developmental delay; speech } \\
\text { impairment; ataxia; happy demeanor and } \\
\text { excessive laughter }\end{array}$ \\
\hline Cri-du-chat syndrome & $5 \mathrm{p}$ & $1: 15,000-50,000$ & $>97 \%$ & $>99 \%$ & $\begin{array}{l}\text { Developmental delay; microcephaly; } \\
\text { dysmorphic features; hearing defects; short } \\
\text { statures; ADHD; a high pitched, cat-like cry }\end{array}$ \\
\hline 1p36 deletion & $1 \mathrm{p} 36$ & $1: 5000$ & $>97 \%$ & $>99 \%$ & $\begin{array}{l}\text { Developmental delay; dysmorphic craniofacial } \\
\text { features; hypotonia; seizures; congenital heart } \\
\text { defects }\end{array}$ \\
\hline
\end{tabular}

Fetal cfDNA for prenatal diagnosis of monogenic disorders

New emerging genomic technology has allowed an improvement of NIPT application in prenatal diagnosis. The rapid development of next generation sequencing (NGS) technologies such as whole genome/exome sequencing, opens a new opportunity to provide genetic analysis for diagnosis of recessive, $\mathrm{X}$-linked and dominant inherited conditions. The sequencing-based new approach could be used to detect rare diseases, including monogenetic diseases in a non-invasively manner. This approach has great potential to be wildly used in the worldwide with the decreasing in sequencing costs, and therefore play an incredible role to prevent rare diseases. The research of monogenic disease shows advantage because the analysis is targeted and in presence of positive results could be considered diagnostic, reducing the access to invasive testing. ${ }^{37}$ Differently, when testing for aneuploidy, the confirmation of an abnormal result is required throughout invasive testing because, as sovramentioned, cfDNA is a mix of maternal and fetal cfDNA. The fetal component released from the placenta may reflect confined cell lines ("confined placental mosaicism"). ${ }^{11-13}$ The first success of NIPT for monogenic disorder diagnosis was the exclusion or identification of paternally inherited variants or de novo mutations. ${ }^{38}$ For these disorders NIPT is based on the detection or exclusion of the paternal mutation in the cfDNA. This approach has been used in the diagnosis of Huntington's disease; 39,40 myotonic dystrophy 41 and early onset primary dystonia I. ${ }^{42}$ In disorders associated to trinucleotide repeat expansions, detection of closely linked polymorphic regions has been used to overcome parents' similar allele size. Li et al. used NIPT to identify point mutations inherited from the father for beta-thalassemia. They reported high sensitivity $(100 \%)$ and specificity $(93.8 \%)$ by size-fractionating cfDNA in maternal plasma followed by a PCR approach that did not amplify the normal maternal allele. ${ }^{43}$ Detection of a fetus with an autosomal dominant disorder with a maternally inherited mutation is much more technically difficult because the fetal genotype in the cfDNA needs to be identified in the presence of an excess maternal DNA. There are some autosomal dominant disorders where a new mutation is relatively common and the detection of the mutation in cfDNA can provide a diagnosis. Some of these mutations could be suspected by ultrasound findings like in skeletal dysplasia. One such example is achondroplasia where a single mutation in the FGFR 3 gene, c. $1138 \mathrm{G}>$ A (p.Gly380Arg), accounts for $98 \%$ of all cases. ${ }^{44}$ Ultrasound findings can sometimes be suggestive of achondroplasia and a non-invasive test that looks specifically for this mutation in cfDNA can be carried out. ${ }^{45,} 46$ Initially polymerase chain reaction with restriction enzyme 
digest (PCRRED) was used for clinical research in NIPT for a small proportion of mutations. However, as interpretation may vary between operators, it had an inconclusive rate of around $8 \%$, and was not universally adaptable and applicable to all mutations. ${ }^{47}$ Another drawback is that only one mutation at a time can be detected and this may be not useful when offering prenatal diagnosis to find an unknow mutation, for example in presence of ultrasound abnormalities that may be caused by a number of different mutations. The use of NGS improve the diagnosis for paternally inherited and de-novo dominant disease through the use of panels designed to detect multiple mutations and detected mutations in cases where PCR-RED had not. ${ }^{30}$ This approach was introduced into UK NHS practice in 2014.

When both parents are carriers for an autosomal recessive disorder, mutation absence would confirm an unaffected carrier or normal fetus. To identify an affected fetus is otherwise necessary to quantify the relative numbers of the alleles present in the cf-DNA and establish that there is a statistically significant excess of one type over another, consistent with a presence of one of the two mutations being present in the fetus. 48 This problem is solved by the assessment of the relative quantities of mutant and wild-type alleles, which can be achieved by using relative mutation dosage (RMD) and relative haplotype dosage analysis (RHDO).49,50 A sex-linked or sex-limited genetic disorder can frequently be excluded early in pregnancy simply by establishing that the fetus is not of the at-risk gender. The detection of cfDNA derived from the Y-chromosome provides a highly accurate determination of fetal sex from as early as 7 weeks gestational age which is earlier than gender can be reliably determined by ultrasound. Additional diagnostic testing can then be limited to only those at-risk cases. This practical approach has been used for a broad range of X-linked disorders such as hemophilia and Duchene muscular dystrophy. $38,51-53$

There are several limitations when using NIPT: first, the low concentration of fetal cfDNA circulating with the relatively abundant maternal cfDNA; the need for highly sensitive methodologies with a broad applicability for different fami- lies; and finally other very important limitation is the cost. Next generation sequencing is also beginning to improve diagnosis in fetuses with unexpected abnormalities that are identified in around $3 \%$ of pregnancies. ${ }^{54}$ Whole exome sequencing (WES) sequences the DNA regions containing the protein-coding exons, which contain $>85 \%$ of all disease-causing mutations. In recent studies emerges that use WES is as a tool to successfully identify pathogenic variants in fetuses euploid with structural sonographic abnormalities. ${ }^{55}$ Benefits of exome sequencing include improving parental counselling, pregnancy and postnatal management; ${ }^{56,57}$ prenatally identification of molecular genetic disorders may also facilitate targeted in-utero treatment. Problems associated with exome sequencing correlate with counselling issues, for example identification of secondary or incidental findings unrelated to the fetal phenotype like cancer predisposition genes. WES offers incomplete coverage of many genes and this may compromise the interpretation of sequencing results. The cost of prenatal WES has not been formally evaluated, but it is high.

\section{Current guidelines for the use of NIPT}

SMFM (the Society for Maternal Fetal Medicine), ACOG (the American Congress of Obstetricians and Gynecologists) and numerous professional societies have published recommendations regarding the appropriate application of cfDNA screening in pregnancy.

The first guidelines of all major societies were published in 2011 and suggested to limit the use of cfDNA screening only to those pregnancies at increased risk of aneuploidy:

- age 35 years or older at the time of delivery;

- ultrasound findings that suggest an increased risk of aneuploidy;

- history of a previous pregnancy with trisomy;

- positive first or second trimester screening tests for aneuploidy;

- parental balanced Robertsonian translocation with increased risk of trisomy 21 or $13.58,59$

In a 2015 committee opinion, ACOG and SMFM acknowledged that patients may choose cfDNA screening regardless of their risk status and should receive pre-test and post-test coun- 
seling. ${ }^{60}$ Pre-test counseling should include both information about commonly detected chromosome arrangement, personal risk factors, both information on the difference between screening and diagnostic testing with a review of available testing options and information about detection rates, false-positive rates, and positive and negative predictive values. ${ }^{61}$

Post counseling advice should be offered in all cases. For patients with negative results, reassurance should be provided along with a discussion that a negative result does not eliminate the possibility that the pregnancy has a genetic condition or birth defect. Patients with positive results on any screening test should be referred for additional genetic counseling to discuss available diagnostic testing options. All patients with discordant results should be referred to an appropriately trained professional for further counseling and review of additional testing options. ${ }^{62}$

The SMFM also recommended that cfDNA microdeletion screening should not be routinely offered; 21 indeed, screening for conditions with such low prevalence will inevitably result in false positive results.

Finally, both SMFM and ACOG do not recommend the use of cfDNA in multiple gestations as suggested by preliminary studies since larger prospective studies are needed. ${ }^{63}$

\section{NIPT and multifetal gestations}

Using any maternal blood-based marker as a screening tool can be challenging in twin pregnancies because in both biochemical and DNAbased screening, the abnormal levels of analytes or DNA fragments from an aneuploid fetus may be masked by the euploid co-twin. ${ }^{63}$

In literature, only five studies have reported the performance of cfDNA screening in twin pregnancies. ${ }^{64-68}$ Whereas pooled detection rates in the most recent meta-analysis are reported to be $100 \%$, the number of studies included limits the generalizability of these results. ${ }^{28}$

Since there is no data regarding the performance of cfDNA aneuploidy screening in higherorder multiple gestations, it should not be offered and aneuploidy screening for these pregnancies should be limited to ultrasound markers only.

In conclusion, the use of NIPT for the diagno- sis of monogenic disorders is not suitable in multiple pregnancies because a conclusive diagnosis is currently not possible to determine whether one or both twins were affected; its use could be useful in cases where discordant ultrasound findings are present. ${ }^{37}$

\section{Economic and social impact}

cfDNA screening has transformed the landscape of prenatal screening for chromosomal disorders. This technology is continuing to expand with many studies currently on-going on this topic to improve screening for genome-wide alterations. It is of the utmost importance for obstetric providers receive appropriate genetics training. Clear and concise patient educational brochure should be available in medical centers where the test is offered.

cfDNA screening has already had a significant population-wide impact on the uptake of conventional screening and diagnostic testing and is rapidly becoming a first-line screening test in some high-income populations. ${ }^{69}$ The very low falsepositive rates associated with cfDNA screening have led to a reduction in the number of diagnostic invasive procedures performed. One study in the USA reported that the number of amniocenteses performed fell by $23.6-50 \%$ and CVS by $14.2-65.7 \%$ after the introduction of cfDNA screening..$^{70}$ Similarly, in Australia the total number of amniocenteses fell by $51 \%$ and CVS by $37 \%$, representing the largest fall in number of invasive procedures in 20 years. ${ }^{71}$

Government-funding screening programs are rapidly incorporating the use of this new technology into their screening algorithms. ${ }^{72,} 73$ In countries without universal health coverage, despite the high detection rate, at present the cost of NIPT remains still too high to be used as primary test of screening for fetal aneuploidies. Therefore, cfDNA test could be used in association to first trimester combined screening in a contingent model where first-trimester combined testing is offered to all patients as a triage and assessment by cfDNA as a secondary test in a smaller proportion of pregnancies. ${ }^{74}$ The inclusion of a contingent screening policy could make cfDNA cost-effective as demonstrated recently in literature. ${ }^{75}$ 


\section{Conclusions}

The NIPT is making revolution in prenatal diagnosis. CfDNA based screening for the common autosomal aneuploidies is the best screening method for trisomy 21 to date. However, women who choose fetal cfDNA technology should be counseled that the test remains a screening test for aneuploidy at this time. Many commercial providers now offer analyses for sub-chromosomal aneuploidies, but we are still at the beginning. No provider has thoroughly validated their tests to a statistically significant level, due to the rare occurrence of these chromosomal abnormalities. Emerging genomic technologies, largely based around next generation sequencing, are offering promise for safer prenatal genetic diagnosis, however these innovative approaches will improve screening for fetal aneuploidies of single gene disorders at an early gestational stage without the need for invasive testing and improve our ability to detect monogenic disorders as the aetiology of fetal abnormalities. This represents a challenge as well as an oppurtunity for clinicians and scientists. Furthermore, as larger proportions of patients with genetic disease are identified we should be ready to offer appropriate genetic counselling to families and potential parents.

\section{References}

1. Benn P, Cuckle H, Pergament E. Non-invasive prenatal testing for aneuploidy: current status and future prospects. Ultrasound Obstet Gynecol 2013;42:15-33.

2. Ghaffari SR, Tahmasebpour AR, Jamal A, Hantoushzadeh $\mathrm{S}$, Eslamian L, Marsoosi V, et al. First-trimester screening for chromosomal abnormalities by integrated application of nuchal translucency, nasal bone, tricuspid regurgitation and ductus venosus flow combined with maternal serum free $\beta$-hCG and PAPP-A: a 5-year prospective study. Ultrasound Obstet Gynecol 2012;39:528-34.

3. Morris JK, Wald NJ, Mutton DE, Alberman E. Comparison of models of maternal age-specific risk for Down syndrome live births. Prenat Diagn 2003;23:252-8.

4. Nicolaides KH. Screening for fetal aneuploidies at 11 to 13 weeks. Prenat Diagn 2011;31:7-15.

5. Ferguson-Smith MA, Yates JR. Maternal age specific rates for chromosome aberrations and factors influencing them: report of a collaborative european study on 52965 amniocenteses. Prenat Diagn 1984;4:5-44.

6. Wald NJ, Cuckle HS, Densem JW, Nanchahal K, Royston $\mathrm{P}$, Chard T, et al. Maternal serum screening for Down's syndrome in early pregnancy. BMJ 1988;297:883-7.

7. Wald NJ, Rodeck C, Hackshaw AK, Walters J, Chitty L, Mackinson AM; SURUSS Research Group. First and second trimester antenatal screening for Down's syndrome: the results of the Serum, Urine and Ultrasound Screening Study (SURUSS). Health Technol Assess 2003;7:1-77.

8. Benn PA, Egan JF, Fang M, Smith-Bindman R. Changes in the utilization of prenatal diagnosis. Obstet Gynecol 2004; 103:1255-60.

9. Haddow JE, Palomaki GE, Knight GJ, Williams J, Pulkkinen A, Canick JA, et al. Prenatal screening for Down's syndrome with use of maternal serum markers. N Engl J Med 1992;327:588-93.

10. Chitty LS, Bianchi DW. Noninvasive prenatal testing: the paradigm is shifting rapidly. Prenat Diagn 2013;33:511-3.

11. Lo YM, Corbetta N, Chamberlain PF, Rai V, Sargent IL, Redman CW, et al. Presence of fetal DNA in maternal plasma and serum. Lancet 1997;350:485-7.

12. Lui YY, Chik KW, Chiu RW, Ho CY, Lam CW, Lo YM Predominant hematopoietic origin of cell-free DNA in plasma and serum after sex-mismatched bone marrow transplantation. Clin Chem 2002;48:421-7.

13. Alberry M, Maddocks D, Jones M, Abdel Hadi M, AbdelFattah S, Avent N, et al. Free fetal DNA in maternal plasma in anembryonic pregnancies: confirmation that the origin is the trophoblast. Prenat Diagn 2007;27:415-8.

14. Lun FM, Chiu RW, Chan KC, Leung TY, Lau TK, Lo YM. Microfluidics digital PCR reveals a higher than expected fraction of fetal DNA in maternal plasma. Clin Chem 2008;54:1664-72.

15. Chan KC, Zhang J, Hui AB, Wong N, Lau TK, Leung TN, et al. Size distributions of maternal and fetal DNA in maternal plasma. Clin Chem 2004;50:88-92.

16. Chen EZ, Chiu RW, Sun H, Akolekar R, Chan KC, Leung TY, et al. Noninvasive prenatal diagnosis of fetal trisomy 18 and trisomy 13 by maternal plasma DNA sequencing. PLoS One 2011;6:e21791.

17. Schuster SC. Next-generation sequencing transforms today's biology. Nat Methods 2008;5:16-8.

18. Lun FM, Jin YY, Sun H, Leung TY, Lau TK, Chiu RW, et al. Noninvasive prenatal diagnosis of a case of Down syndrome due to robertsonian translocation by massively parallel sequencing of maternal plasma DNA. Clin Chem 2011;57:917-9.

19. Srinivasan A, Bianchi DW, Huang H, Sehnert AJ, Rava RP. Noninvasive detection of fetal subchromosome abnormalities via deep sequencing of maternal plasma. Am J Hum Genet 2013;92:167-76.

20. Revello R, Sarno L, Ispas A, Akolekar R, Nicolaides KH Screening for trisomies by cell-free DNA testing of maternal blood: consequences of a failed result. Ultrasound Obstet Gynecol 2016;47:698-704.

21. Sparks AB, Struble CA, Wang ET, Song K, Oliphant A. Noninvasive prenatal detection and selective analysis of cellfree DNA obtained from maternal blood: evaluation for trisomy 21 and trisomy 18. Am J Obstet Gynecol 2012;206:319.e1-9.

22. Sparks AB, Wang ET, Struble CA, Barrett W, Stokowski $\mathrm{R}$, McBride C, et al. Selective analysis of cell-free DNA in maternal blood for evaluation of fetal trisomy. Prenat Diagn 2012;32:3-9.

23. Hui L. Noninvasive prenatal testing for aneuploidy using cell-free DNA - New implications for maternal health. Obstet Med 2016;9:148-52.

24. Haghiac M, Vora NL, Basu S, Johnson KL, Presley L, Bianchi DW, et al. Increased death of adipose cells, a path to release cell-free DNA into systemic circulation of obese women. Obesity (Silver Spring) 2012;20:2213-9. 
25. Chan RW, Jiang P, Peng X, Tam LS, Liao GJ, Li EK, et al. Plasma DNA aberrations in systemic lupus erythematosus revealed by genomic and methylomic sequencing. Proc Natl Acad Sci USA 2014;111:E5302-11.

26. Bianchi DW, Chudova D, Sehnert AJ, Bhatt S, Murray $\mathrm{K}$, Prosen TL, et al. Noninvasive prenatal testing and incidental detection of occult maternal malignancies. JAMA 2015;314:162-9.

27. Curnow KJ, Wilkins-Haug L, Ryan A, Kırkızlar E, Stosic M, Hall MP, et al. Detection of triploid, molar, and vanishing twin pregnancies by a single-nucleotide polymorphism-based noninvasive prenatal test. Am J Obstet Gynecol 2015;212:79. e1-9.

28. Gil MM, Accurti V, Santacruz B, Plana MN, Nicolaides KH. Analysis of cell-free DNA in maternal blood in screening for aneuploidies: updated meta-analysis. Ultrasound Obstet Gynecol 2017;50:302-14.

29. Hillman SC, Pretlove S, Coomarasamy A, McMullan DJ, Davison EV, Maher ER, et al. Additional information from array comparative genomic hybridization technology over conventional karyotyping in prenatal diagnosis: a systematic review and meta-analysis. Ultrasound Obstet Gynecol 2011;37:6-14.

30. Wapner RJ, Martin CL, Levy B, Ballif BC, Eng CM, Zachary JM, et al. Chromosomal microarray versus karyotyping for prenatal diagnosis. N Engl J Med 2012;367:2175-84.

31. Lichtenbelt KD, Knoers NV, Schuring-Blom GH. From karyotyping to array-CGH in prenatal diagnosis. Cytogenet Genome Res 2011;135:241-50.

32. Wapner RJ, Babiarz JE, Levy B, Stosic M, Zimmermann $\mathrm{B}$, Sigurjonsson S, et al. Expanding the scope of noninvasive prenatal testing: detection of fetal microdeletion syndromes. Am J Obstet Gynecol 2015;212:332.e1-9.

33. Peters D, Chu T, Yatsenko SA, Hendrix N, Hogge WA, Surti U, et al. Noninvasive prenatal diagnosis of a fetal microdeletion syndrome. N Engl J Med 2011;365:1847-8.

34. Jensen TJ, Dzakula Z, Deciu C, van den Boom D, Ehrich $\mathrm{M}$. Detection of microdeletion $22 \mathrm{q} 11.2$ in a fetus by next-generation sequencing of maternal plasma. Clin Chem 2012;58:1148-51.

35. Gross SJ, Stosic M, McDonald-McGinn DM, Bassett AS, Norvez A, Dhamankar R, et al. Clinical experience with single-nucleotide polymorphism-based non-invasive prenatal screening for $22 \mathrm{q} 11.2$ deletion syndrome. Ultrasound Obstet Gynecol 2016;47:177-83.

36. Helgeson J, Wardrop J, Boomer T, Almasri E, Paxton WB, Saldivar JS, et al. Clinical outcome of subchromosomal events detected by whole-genome noninvasive prenatal testing. Prenat Diagn 2015;35:999-1004.

37. Hayward J, Chitty LS. Beyond screening for chromosomal abnormalities: advances in non-invasive diagnosis of single gene disorders and fetal exome sequencing. Semin Fetal Neonatal Med 2018;23:94-101.

38. Benn P. Non-Invasive Prenatal Testing Using Cell Free DNA in Maternal Plasma: Recent Developments and Future Prospects. J Clin Med 2014;3:537-65.

39. González-González MC, Trujillo MJ, Rodríguez de Alba M, García-Hoyos M, Lorda-Sánchez I, Díaz-Recasens J, et al. Huntington disease-unaffected fetus diagnosed from maternal plasma using QF-PCR. Prenat Diagn 2003;23:232-4.

40. Rodríguez de Alba M, Bustamante-Aragonés A, Perlado $\mathrm{S}$, Trujillo-Tiebas MJ, Díaz-Recasens J, Plaza-Arranz J, et al. Noninvasive prenatal diagnosis of monogenic disorders. Expert Opin Biol Ther 2012;12(Suppl 1):S171-9.

41. Amicucci P, Gennarelli M, Novelli G, Dallapiccola B.
Prenatal diagnosis of myotonic dystrophy using fetal DNA obtained from maternal plasma. Clin Chem 2000;46:301-2.

42. Meaney C, Norbury G. Noninvasive prenatal diagnosis of early onset primary dystonia I in maternal plasma. Prenat Diagn 2009;29:1218-21.

43. Li Y, Di Naro E, Vitucci A, Zimmermann B, Holzgreve W, Hahn S. Detection of paternally inherited fetal point mutations for beta-thalassemia using size-fractionated cell-free DNA in maternal plasma. JAMA 2005;293:843-9.

44. Pauli RM. Achondroplasia. In: Pagon RA, Adam MP, Bird TD, Dolan CR, Fong CT, Smith RJH, et al., editors. GeneReviews ${ }^{\mathrm{TM}}$. Seattle, WA: University of Washington Seattle; 2018.

45. Saito H, Sekizawa A, Morimoto T, Suzuki M, Yanaihara T. Prenatal DNA diagnosis of a single-gene disorder from maternal plasma. Lancet 2000;356:1170.

46. Chitty LS, Griffin DR, Meaney C, Barrett A, Khalil A, Pajkrt E, et al. New aids for the non-invasive prenatal diagnosis of achondroplasia: dysmorphic features, charts of fetal size and molecular confirmation using cell-free fetal DNA in maternal plasma. Ultrasound Obstet Gynecol 2011;37:283-9.

47. Minear MA, Lewis C, Pradhan S, Chandrasekharan S. Global perspectives on clinical adoption of NIPT. Prenat Diagn 2015;35:959-67.

48. Lun FM, Tsui NB, Chan KC, Leung TY, Lau TK, Charoenkwan $\mathrm{P}$, et al. Noninvasive prenatal diagnosis of monogenic diseases by digital size selection and relative mutation dosage on DNA in maternal plasma. Proc Natl Acad Sci USA 2008;105:19920-5.

49. Parks M, Court S, Bowns B, Cleary S, Clokie S, Hewitt $\mathrm{J}$, et al. Non-invasive prenatal diagnosis of spinal muscular atrophy by relative haplotype dosage. Eur J Hum Genet 2017;25:416-22.

50. Parks M, Court S, Cleary S, Clokie S, Hewitt J, Williams $\mathrm{D}$, et al. Non-invasive prenatal diagnosis of Duchenne and Becker muscular dystrophies by relative haplotype dosage. Prenat Diagn 2016;36:312-20.

51. Madan $\mathrm{K}$, Breuning $\mathrm{MH}$. Impact of prenatal technologies on the sex ratio in India: an overview. Genet Med 2014; 16:425-32.

52. Benn PA. Prenatal technologies and the sex ratio. Genet Med 2014;16:433-4.

53. Chapman AR, Benn PA. Noninvasive prenatal testing for early sex identification: a few benefits and many concerns. Perspect Biol Med 2013;56:530-47.

54. Calzolari E, Barisic I, Loane M, Morris J, Wellesley D, Dolk H, et al. Epidemiology of multiple congenital anomalies in Europe: a EUROCAT population-based registry study. Birth Defects Res A Clin Mol Teratol 2014;100:270-6.

55. Best S, Wou K, Vora N, Van der Veyver IB, Wapner R, Chitty LS. Promises, pitfalls and practicalities of prenatal whole exome sequencing. Prenat Diagn 2018;38:10-9.

56. Retterer K, Juusola J, Cho MT, Vitazka P, Millan F, Gibellini $\mathrm{F}$, et al. Clinical application of whole-exome sequencing across clinical indications. Genet Med 2016;18:696-704.

57. Illsinger S, Das AM. Impact of selected inborn errors of metabolism on prenatal and neonatal development. IUBMB Life 2010;62:403-13.

58. American College of Obstetricians and Gynecologists Committee on Genetics. Committee Opinion No. 545: noninvasive prenatal testing for fetal aneuploidy. Obstet Gynecol 2012;120:1532-4.

59. Gregg AR, Skotko BG, Benkendorf JL, Monaghan KG, Bajaj K, Best RG, et al. Noninvasive prenatal screening for fetal aneuploidy, 2016 update: a position statement of the 
American College of Medical Genetics and Genomics. Genet Med 2016;18:1056-65.

60. Society for Maternal-Fetal Medicine (SMFM) Publications Committee. Electronic address: pubs@smfm.org. \#36: Prenatal aneuploidy screening using cell-free DNA. Am J Obstet Gynecol 2015;212:711-6.

61. Sachs A, Blanchard L, Buchanan A, Norwitz E, Bianchi DW. Recommended pre-test counseling points for noninvasive prenatal testing using cell-free DNA: a 2015 perspective. Prenat Diagn 2015;35:968-71.

62. Harris S, Reed D, Vora NL. Screening for fetal chromosomal and subchromosomal disorders. Semin Fetal Neonatal Med 2018;23:85-93.

63. Prats P, Rodríguez I, Comas C, Puerto B. Systematic review of screening for trisomy 21 in twin pregnancies in first trimester combining nuchal translucency and biochemical markers: a meta-analysis. Prenat Diagn 2014;34:1077-83.

64. Lau TK, Jiang F, Chan MK, Zhang H, Lo PS, Wang W. Non-invasive prenatal screening of fetal Down syndrome by maternal plasma DNA sequencing in twin pregnancies. J Matern Fetal Neonatal Med 2013;26:434-7.

65. Huang X, Zheng J, Chen M, Zhao Y, Zhang C, Liu L, et al. Noninvasive prenatal testing of trisomies 21 and 18 by massively parallel sequencing of maternal plasma DNA in twin pregnancies. Prenat Diagn 2014;34:335-40.

66. Benachi A, Letourneau A, Kleinfinger P, Senat MV, Gautier E, Favre R, et al.; Collaborative SEquençage a Haut Debit et Aneuploidies (SEHDA) Study Group. Cell-free DNA analysis in maternal plasma in cases of fetal abnormalities detected on ultrasound examination. Obstet Gynecol 2015;125:1330-7.

67. Sarno L, Revello R, Hanson E, Akolekar R, Nicolaides KH. Prospective first-trimester screening for trisomies by cell-free DNA testing of maternal blood in twin pregnancy. Ultrasound Obstet Gynecol 2016;47:705-11.
68. Tan Y, Gao Y, Lin G, Fu M, Li X, Yin X, et al. Noninvasive prenatal testing (NIPT) in twin pregnancies with treatment of assisted reproductive techniques (ART) in a single center. Prenat Diagn 2016;36:672-9.

69. Hui L, Hutchinson B, Poulton A, Halliday J. Populationbased impact of noninvasive prenatal screening on screening and diagnostic testing for fetal aneuploidy. Genet Med 2017; 19:1338-45.

70. Platt LD, Janicki MB, Prosen T, Goldberg JD, Adashek $\mathrm{J}$, Figueroa $\mathrm{R}$, et al. Impact of noninvasive prenatal testing in regionally dispersed medical centers in the United States. Am J Obstet Gynecol 2014;211:368.e1-7.

71. Robson SJ, Hui L. National decline in invasive prenatal diagnostic procedures in association with uptake of combined first trimester and cell-free DNA aneuploidy screening. Aust N Z J Obstet Gynaecol 2015;55:507-10.

72. Oepkes D, Page-Christiaens GC, Bax CJ, Bekker MN, Bilardo CM, Boon EM, et al.; and for the Dutch NIPT Consortium. Trial by Dutch laboratories for evaluation of noninvasive prenatal testing. Part I-clinical impact. Prenat Diagn 2016;36:1083-90.

73. Chitty LS, Wright D, Hill M, Verhoef TI, Daley R, Lewis $\mathrm{C}$, et al. Uptake, outcomes, and costs of implementing non-invasive prenatal testing for Down's syndrome into NHS maternity care: prospective cohort study in eight diverse maternity units. BMJ 2016;354:i3426-12.

74. Cuckle H, Benn P, Pergament E. Maternal cfDNA screening for Down syndrome - a cost sensitivity analysis. Prenat Diagn 2013;33:636-42.

75. Morris S, Karlsen S, Chung N, Hill M, Chitty LS. Modelbased analysis of costs and outcomes of non-invasive prenatal testing for Down's syndrome using cell free fetal DNA in the UK National Health Service. PLoS One 2014;9:e93559.

Conflicts of interest.-The authors certify that there is no conflict of interest with any financial organization regarding the material discussed in the manuscript.

Article first published online: October 11, 2018. - Manuscript accepted: September 17, 2018. - Manuscript received: September 1, 2018. 